\title{
ПОНЯТИЕ И ОСОБЕННОСТИ ИСПОЛЬЗОВАНИЯ ГРАДОСТРОИТЕЛЬНЫХ ОГРАНИЧЕНИЙ, УСТАНАВЛИВАЕМЫХ НА ТЕРРИТОРИИ ГОРОДА МОСКВЫ
}

\author{
В. Ю. Метальников \\ Национальный исследовательский университет \\ "Высшая школа экономики" \\ Поступила в редакцию 6 сентября 2021 г.
}

\begin{abstract}
Аннотация: исследуются понятие градостроительных ограничений, их виды. Расслатриваются особенности установления градостроительных ограничений органали исполнительной власти г. Москвы. Обосновываетсл, что установление требований к осуществлению градостроительной деятельности органали исполнительной власти г. Москвы, ограничивающих деятельность субъектов градостроительньх правоотношений, представляет собой совокупность особых способов управляющего воздействия. Ключевые слова: градостроительные ограничения, органы исполнительной власти, государственное управление, управляющее воздействие, градостроительная деятельность, методь управления.
\end{abstract}

Abstract: the article discusses the concept of urban planning restrictions, their types. The features of urban planning functions of the executive power of the city of Moscow are considered. It is substantiated that the establishment of activities for the executive activities of the executive power of the city of Moscow, limiting the subjects of urban planning legal relations, is a set of special methods of control.

Key words: urban planning restrictions, executive authorities, public administration, management influence, urban planning activities, management methods.

Действующее законодательство устанавливает большой перечень ограничений по использованию земельных участков и объектов капитального строительства, которые создают правовые барьеры для осуществления градостроительной деятельности. Вместе с тем на федеральном уровне не закреплено единого понятия, обобщающего такие ограничения. Пределы ограничений также не установлены.

Возможность установления ограничений использования земельных участков предусматривалась еще советским земельным законодательством. О. А. Самончик отмечала, что «в советском земельном праве выделялись общие и специальные ограничения прав землепользователей. Под первыми понималась общая обязанность всех землепользователей не совершать на своем участке действий, которые хотя и соответствовали общему характеру земельных прав, но могли бы нарушить интересы соседей. Специальными ограничениями являлись ограничения, устанав-

(C) Метальников В. Ю., 2021 


\section{Вестник ВГУ. Серия: Право}

ливаемые в интересах транспорта, промышленных предприятий, курортов, заповедников, заказников и т. д. ${ }^{1}$

Под ограничениями использования объектов капитального строительства (недвижимости) исследователи предлагают понимать «нормы, устанавливающие пределы реализации имущественных прав с целью обеспечения преимущественно публичных интересов либо содержащие требования о воздержании от совершения определенных действий, которые предусмотрены законодательством и не применяются в отношении других земельных участков, имеющих аналогичное целевое назначение» ${ }^{2}$.

Попытка сформулировать общее понятие, объединяющее все виды градостроительных ограничений (включающих ограничения по использованию земельных участков и (или) объектов капитального строительства), содержится в методических рекомендациях по разработке проектов генеральных планов поселений и городских округов. В данных методических рекомендациях предлагается довольно широкое понятие градостроительных ограничений. Под градостроительными ограничениями рекомендуется понимать «ряд требований, ограничивающих градостроительную деятельность в конкретном территориальном образовании. $\mathrm{K}$ таким ограничениям относятся: зоны с особыми условиями использования территории и иные территории с установленными ограничениями в соответствии с действующим законодательством» ${ }^{3}$.

Исчерпывающий перечень зон с особыми условиями использования территории содержится в Земельном кодексе РФ. В своем исследовании Е. C. Болтанова отмечает, что «общая задача установления зон с особыми условиями использования - определение в пределах их замкнутых границ правового режима, характеризуемого дополнительными ограничениями, запретами в использовании земельных участков (включая всё, специальными фредеральными законами), не свойственными сопряженным территориям» ${ }^{4}$.

Поскольку перечень зон с особыми условиями использования территории является закрытым, а ограничения в границах таких зон подробно регулируются действующим законодательством, данный вид градострои-

${ }^{1}$ См.: Салончик O. А. Правовое регулирование ограничений земельных прав сельскохозяйственных предприятий : дис. ... канд. юрид. наук. М., 1986. С. 100101.

${ }^{2}$ Цит. по: Чередников А. В., Никишин В. В. Определение правового режима недвижимости в российском законодательстве // Рос. юрид. журнал. 2021. № 1. C. 203-211.

${ }^{3}$ Методические рекомендации по разработке проектов генеральных планов поселений и городских округов : утв. приказом Минрегиона РФ от 26 мая 2011 г. № 244. Доступ из справ.-правовой системы «КонсультантПлюс».

${ }^{4}$ Болтанова E. C. Ограничение прав в связи с установлением зоны с особыми условиями использования // Имущественные отношения в Российской Федерации. 2019. № 5. С. 55-65. 
Иным образом обстоят дела с понятием «иные территории с установленными ограничениями», которое является неопределенным с точки зрения его содержания и не раскрывается в действующем законодательстве.

Градостроительный кодекс Российской Федерации (далее - ГрК РФ) использует общую формулировку «ограничения использования земельных участков и объектов капитального строительства, устанавливаемые в соответствии с законодательством Российской Федерации». ГрК РФ выделяет ограничения использования земельных участков и ограничения использования объектов капитального строительства. Однако содержание и объем таких ограничений ГрК РФ также не раскрывает.

Вместе с тем, чтобы определить существующие градостроительные ограничения в границах определенной территории, достаточно обратиться к правилам землепользования и застройки и градостроительному регламенту, который является составной частью правил землепользования и застройки.

Как отмечал Конституционный Суд РФ в постановлении от 28 марта 2017 г. № 10-П, «предусматриваемые в составе правил землепользования и застройки территориальные зоны и градостроительные регламенты, в неразрывном единстве с их общей частью, предопределяют ... ограничения использования земельных участков и объектов капитального строительства».

В научных работах отмечается также роль правил землепользования и застройки как документа, содержащего имеющиеся ограничения использования земельных участков и объектов капитального строительства. Исследователи указывают, что «конкретные стимулы и ограничения, дозволения и запреты правообладателям земельных участков в границах населенных пунктов устанавливаются правилами землепользования и застройки» ${ }^{6}$.

Некоторые исследователи идут дальше, считая, что «эффрективность правового регулирования может быть обеспечена посредством объединения (системного перечисления) всей совокупности необходимых правовых предписаний в одном документе - правилах землепользования и за-

${ }^{5}$ По делу о проверке конституционности части 4.1 статьи 63 Градостроительного кодекса Российской Федерации и статьи 23 Федерального закона «О внесении изменений в Кодекс Российской Федерации об административных правонарушениях и отдельные законодательные акты Российской Федерации и о признании утратившими силу отдельных положений законодательных актов Российской Федерации в связи с уточнением полномочий государственных органов и муниципальных органов в части осуществления государственного контроля (надзора) и муниципального контроля» в связи с запросом Законодательного Собрания Санкт-Петербурга : постановление Конституционного Суда РФ от 28 марта 2017 г. № 10-П // Собр. законодательства Рос. Федерации. 2017. № 15 (ч. 7). Ст. 2284.

${ }^{6}$ Актуальные проблемы теории земельного права России / Н. Н. Абанина [и др.]. М., 2020. С. 235. 
стройки, включающих в числе прочего градостроительные регламенты» ${ }^{\text {. }}$ Предлагается также включать «положения иных нормативных правовых актов (нередко имеющих более высокую юридическую силу) с целью их воспроизведения в содержании правил землепользования и застройки для придания им максимальной информативности и максимально полного определения объема прав и обязанностей в отношении соответствующего недвижимого имущества» ${ }^{8}$.

Данное предложение является обоснованным с точки зрения обширной правотворческой практики органов власти в сфере земельного и градостроительного законодательства, находящихся в совместном ведении РФ и ее субъектов. Наличие информации о всех ограничениях по использованию земельных участков и (или) объектов капитального строительства является важным условием осуществления градостроительной деятельности с соблюдением требований законодательства. К примеру, некоторые авторы в своих исследованиях отмечают, что «результатом недостаточной информированности уполномоченных органов власти о наличии тех или иных ограничений, которые способны повлиять как на ограничения использования земельных участков, так и на их оборотоспособность, может стать недействительность оснований предоставления земельного участка в собственность, признание постройки самовольной, а также истребование земельного участка из чужого незаконного владения на основании виндикационного иска, подтверждением чему являются многочисленные примеры судебной практики» ${ }^{9}$.

Вместе с тем правила землепользования и застройки содержат информацию о фрактически действующих ограничениях в границах конкретных территорий и не перечисляют возможный перечень таких ограничений в принципе.

Все градостроительные ограничения можно условно разделить на «внутренние градостроительные ограничения» и «внешние градостроительные ограничения».

К внутренним градостроительным ограничениям можно отнести ограничения, устанавливаемые в градостроительных документах, предусмотренных ГрК РФ. К градостроительным документам, устанавливающим внутренние градостроительные ограничения, относятся: документы территориального планирования, нормативы градостроительного проектирования, правила землепользования и застройки, документация по планировке территории. Одним из основных элементов содержания внутренних градостроительных ограничений является «параметрирование

7 Чередников А. В., Никишин В. В. Определение правового режима недвижимости в российском законодательстве // Рос. юрид. журнал. 2021. № 1. С. 203-211.

8 Там же.

${ }_{9}^{9}$ Филаткина Ю. Е. Управление юридическими рисками, связанными с ограничением использования и хозяйственного оборота земельных участков // Имущественные отношения в Российской Федерации. 2019. № 3. С. 96-101. 
строительства ${ }^{10}$, которое выражается в закреплении в градостроительной документации системы ограничений на застройку земельных участков.

К внешним градостроительным ограничениям целесообразно относить ограничения, установленные Земельным кодексом РФ (ограничения оборотоспособности земельных участков, зоны с особыми условиями использования территорий), требования технических регламентов, своды правил и иные градостроительные ограничения, установленные законодательством РФ.

Деление градостроительных ограничений на внутренние и внешние осуществляется по основанию их возникновения. К внутренним следует относить ограничения, установленные в ГрК РФ, а к внешним - ограничения, установленные в иных правовых актах, регулирующих градостроительную деятельность.

Как правило, внутренние градостроительные ограничения являются следствием внешних градостроительных ограничений. Так, нахождение земельного участка в границах приаэродромной территории ограничивает предельные параметры разрешенного строительства, которые будут установлены в правилах землепользования и застройки, к примеру по допустимой высотности застройки, а нахождение земельного участка в границах санитарно-защитных зон исключает возможность предусматривать в градостроительных документах размещение жилой застройки в границах таких зон.

Таким образом, под градостроительными ограничениями в широком смысле следует понимать требования к использованию земельных участков и объектов капитального строительства при осуществлении градостроительной деятельности. Объем таких ограничений федеральным законодательством не зафиксирован, что говорит об установлении открытого перечня требований и ограничений к использованию земельных участков и объектов капитального строительства в законодательстве о градостроительной деятельности.

Стоит также отметить, что градостроительные ограничения могут устанавливаться как органами публичной власти феедерального и регионального уровня, так и органами местного самоуправления, за исключением ограничений, возникающих в силу федерального закона (к примеру, водоохранные (рыбоохранные) зоны, прибрежные защитные полосы, защитные зоны объектов культурного наследия) ${ }^{11}$. Из этого следует достаточно обширная практика правового регулирования градостроительных ограничений в субъектах РФ.

Так, несмотря на отсутствие в федеральном законодательстве понятия и содержания градостроительных ограничений, правовые акты

${ }^{10}$ Винницкий А. В., Харинов И. Н. Параметрирование строительства : модернизация регулирования и проблемы устранения избыточных ограничений // Рос. юрид. журнал. 2020. № 6. C. 146-161.

${ }^{11}$ Пункт 1 ст. 106 Земельного кодекса Российской Федерации. 
г. Москвы, регулирующие градостроительную деятельность, содержат понятие, обобщающее градостроительные ограничения, а также определяют содержание градостроительных ограничений в г. Москве.

В Законе г. Москвы от 25 июня 2008 г. № 28 «Градостроительный кодекс города Москвы» (далее - ГрК Москвы) вводится понятие «линии градостроительного регулирования» ${ }^{12}$, которое является собирательным для градостроительных ограничений и включает в себя красные линии, линии, обозначающие установленные границы зон с особыми условиями использования территорий и границы иных территорий, на которых установлены ограничения использования земельных участков и (или) объектов капитального строительства. Понятие и статус красных линий и зон с особыми условиями использования территории установлены в ГрК РФ и Земельном кодексе РФ соответственно. Понятие иных территорий, на которых установлены ограничения использования земельных участков и (или) объектов капитального строительства ГрК Москвы не раскрывается, но дается отсылка на сводный план регулирования использования территории г. Москвы, раскрывающий содержание данных ограничения (далее - СПРИТ).

Сводный план регулирования использования территории г. Москвы ${ }^{13}$ содержит сведения о линиях градостроительного регулирования и границах территорий, обозначенных линиями градостроительного регулирования.

По своей сути СПРИТ является актуальным сводом требований и ограничений, действующих в отношении участков территории г. Москвы, выделяемых линиями градостроительного регулирования. СПРИТ обеспечивает получение применительно к любому участку территории г. Москвы полных и актуальных сведений о том, какие требования и ограничения, установленные в соответствии с законодательством, действуют в отношении этого участка территории.

Ключевой особенностью данного свода является наличие линий градостроительного регулирования, обозначающих гранищы иных территорий, на которых установлены ограничения использования земельных участков и объектов капитального строительства.

Понятие «иные территории, на которых установлены ограничения использования земельных участков и объектов капитального строительства», так же как и понятие «линия градостроительного регулирования», в федеральном законодательстве не содержатся. Наличие в правовых актах г. Москвы данных терминов является особенностью правового регулирования градостроительной деятельности на ее территории.

12 Понятие «линии градостроительного регулирования» и их перечень также содержатся в РДС 30-201-98. Система нормативных документов в строительстве (руководящий документ системы. Инструкция о порядке проектирования и установления красных линий в городах и других поселениях Российской Федерации : принят постановлением Госстроя РФ от 6 апреля 1998 г. № 18-30).

${ }^{13}$ Об утверждении Порядка ведения сводного плана регулирования использования территории города Москвы : постановление правительства Москвы от 16 апреля 2019 г. № 365-ПП. 
СПРИТ включает 14 линий, обозначающих границы иных территорий, на которых установлены ограничения использования земельных участков и объектов капитального строительства. Данные линии отображаются как линии градостроительного плана в г. Москве и вводят дополнительные ограничения использования земельных участков и объектов капитального строительства либо выделяют уже существующие ограничения, установленные фредеральными правовыми актами или правовыми актами г. Москвы.

В фредеральных правовых актах установлены ограничения по использованию земельных участков и объектов капитального строительства в границах: береговых полос, полос отвода железных дорог, лесопарковых зеленых поясах, полосах воздушных подходов на аэродромах, территориях объектов культурного наследия и территориях выявленных объектов культурного наследия, особо охраняемых природных территориях. Границы территорий, находящихся в таких ограничениях, дополнительно выделяются г. Москвой линиями градостроительного регулирования.

Такие ограничения, как технические зоны инженерных коммуникаций и сооружений, технические зоны метрополитена и линии застройки содержатся в постановлении Госстроя РФ $\Phi^{14}$. Данные ограничения также выделяются г. Москвой линиями градостроительного регулирования.

Правовыми актами г. Москвы устанавливаются такие ограничения использования земельных участков и объектов капитального строительства, как территории, зарезервированные для образования особо охраняемых природных территорий, особо охраняемые зеленые территории, объекты природного комплекса г. Москвы, внеуличные пешеходные переходы и зоны транспортных коммуникаций, обозначающие границы территорий, предназначенных и используемых для размещения наземных транспортных коммуникаций (монорельсовый транспорт, подвесная канатная дорога транспортная, фуникулер транспортный, трамвай).

Таким образом, правовые акты г. Москвы подробно регулируют понятие и содержание градостроительных ограничений на ее территории, а также вводят дополнительные ограничения, не предусмотренные правовыми актами федерального уровня, и действующие исключительно на территории г. Москвы.

В научных исследованиях государственное управление градостроительной деятельностью предлагается рассматривать как «специфический вид властной государственной деятельности, содержанием которой является практическая реализация полномочий государства в обозначенной сфрере, направленных на создание условий для устойчивого, комплексного развития территории, ее рациональной организации, и государственный контроль за названной деятельностью» ${ }^{15}$.

${ }^{14}$ Постановление Госстроя РФ от 6 апреля 1998 г. № 18-30.

${ }^{15}$ Бутаева E. M. Юридическая сущность и значение государственного управления градостроительной деятельностью // Гражданин и право. 2011. № 10. С. 69. 
Органы исполнительной власти, осуществляя государственное управление градостроительной деятельностью, применяют различные методы управления. Исследователи отмечают, что «понятие метода государственного управления в теории государственного управления призвано продемонстрировать, с помощью каких основных приемов осуществляется государственное управление» ${ }^{16}$. В научной литературе также отмечается, что «ключевой в понимании методов управления является идея о том, что в них непосредственно проявляется характер управляющего воздействия субъекта управления на объект, характер их взаимосвязи» ${ }^{17}$.

Особый порядок применения методов государственного управления, образующих совокупность способов (приемов) управляющего воздействия реализуется органами исполнительной власти г. Москвы в области градостроительной деятельности.

В системе правовых актов г. Москвы утверждены правовые акты, устанавливающие требования и ограничения по осуществлению градостроительной деятельности. Установление таких требований и ограничений создает особый порядок применения методов государственного управления, образующих совокупность способов (приемов) управляющего воздействия в области градостроительной деятельности.

Поскольку метод управления рассматривается как «совокупность конкретных последовательных операций управляющих органов, целью которых является определенного вида воздействие на управляемые объекты для достижения каких-то намеченных результатов в процессе осуществления исполнительно-распорядительных фрункций государства» ${ }^{18}$, устанавливаемые в правовых актах г. Москвы требования и ограничения по осуществлению градостроительной деятельности, имеющие различное содержание и создающие разные способы применения административных методов, в свою очередь, приводят к образованию совокупности 일 различных способов (приемов) управляющего воздействия на объекты управления.

К примеру, нахождение земельных участков и объектов капитального строительства в границах территорий, на которых установлены требования и ограничения по осуществлению градостроительной деятельности

216 в г. Москве, приводит к отказу уполномоченными органами субъектам градостроительной деятельности в согласовании строительства или реконструкции объектов капитального строительства, в изменении видов разрешенного использования земельных участков или изменении пара-

${ }^{16}$ Соколов $A$. Н. Муниципальное право и государственное управление в России / под ред. А. Г. Пархоменко. М., 2016. С. 51.

${ }^{17}$ Кудрякова О. В., Звягиниева Д. В. Проблемы соответствия административно-восстановительных мер Гражданскому кодексу Российской Федерации // Власть закона. 2018. № 1. С. 144-152.

${ }_{18}$ Маледов А. А. Административно-правовое регулирование контроля и надзора в государственном управлении // Административное право и процесс. 2018. № 1. C. 26-29. 
метров разрешенного строительства либо накладывает на них дополнительные обязательства, от выполнения которых зависит получение необходимых разрешений.

Остановимся наиболее подробно на установленных в правовых актах г. Москвы линиях градостроительного регулирования, обозначающих границы территорий, на которых действуют требования и ограничения по их использованию.

Появление данных линий градостроительного регулирования является особенностью реализации органами исполнительной власти г. Москвы полномочий в области осуществления градостроительной деятельности. Создание СПРИТ и принятие правовых актов г. Москвы, устанавливающих ограничения использования ее территорий является также примером реализации органами исполнительной власти г. Москвы особых способов применения административных методов в области градостроительной деятельности, образующих совокупность способов (приемов) управляющего воздействия.

В правовых актах г. Москвы устанавливаются различные виды ограничений по использованию земельных участков и объектов капитального строительства на территории г. Москвы.

Одним из таких видов ограничений являются территории, зарезервированные для образования особо охраняемых природных территорий. Они образуются по решению правительства Москвы на основании схемы развития и размещения особо охраняемых природных территорий по представлению специально уполномоченного органа правительства Москвы по управлению особо охраняемыми природными территориями в г. Москве. Ограничения использования земельных участков и (или) объектов капитального строительства в границах территорий, зарезервированных для образования особо охраняемых природных территорий установлены Положением о порядке использования земельных участков, зарезервированных для образования особо охраняемых природных территорий в г. Москве (далее - Порядок) ${ }^{19}$.

Согласно п. 6 Порядка границы земельных участков, зарезервированных для образования особо охраняемых природных территорий, закрепляются линиями градостроительного регулирования. Данный пункт является единственным примером, когда установление иных ограничений правовыми актами г. Москвы сопровождается отсылкой на закрепление данных ограничений линиями градостроительного регулирования.

Еще одним видом территорий, имеющим требования и ограничения по их использованию, установленные в правовых актах г. Москвы, являются особо охраняемые зеленые территории.

${ }^{19}$ Об утверждении Положения о порядке использования земельных участков, зарезервированных для образования особо охраняемых природных территорий в городе Москве : постановление правительства Москвы от 31 января 2006 г. № 50ПП. 
После изменения границ между г. Москвой и Московской областью в состав г. Москвы вошли значительные территории лесного фонда ${ }^{20}$.

В целях сохранения средозащитных, климаторегулирующих, санитарно-гигиенических и рекреационных фрункций данных территорий правительство Москвы установило для них особый статус, ограничивающий осуществление градостроительной деятельности ${ }^{21}$.

Особенностью особо охраняемых зеленых территорий в г. Москве является их нахождение исключительно на территориях, присоединенных к г. Москве ${ }^{22}$.

На особо охраняемых зеленых территориях запрещается деятельность, не связанная с сохранением и изучением особо охраняемых зеленых территорий, за исключением деятельности, предусмотренной решением правительства Москвы. Граница особо охраняемых зеленых территорий г. Москвы также выделяется линиями градостроительного регулирования и отображается в СПРИТ.

Другим видом территорий, имеющим требования и ограничения по их использованию, являются объекты природного комплекса г. Москвы.

Необходимо отметить, что в соответствии со ст. 54 ГрК Москвы изменение границ природных и озелененных территорий допускается только при условии соблюдения установленных показателей баланса указанных территорий или увеличения доли природных и озелененных территорий в балансе территорий.

Например, если для осуществления строительства потребуется взять часть земельного участка в границах объекта природного комплекса г. Москвы, то для этого сначала потребуется исключить его из состава объектов природного комплекса и подобрать участок компенсации, равный или больший, чем планируемый к исключению. Более того, данная компенсация должна быть предусмотрена тем же постановлением правительства Москвы, которым предлагается уменьшение территории объекта природного комплекса.

Помимо этого, объекты природного комплекса входят в перечень территорий природного комплекса Москвы с режимами регулирования градостроительной деятельности ${ }^{23}$. Режим регулирования градостроительной деятельности, устанавливаемый в границах объекта природного

${ }^{20}$ Постановление Совета Федерации Федерального Собрания Российской Федерации от 27 декабря 2011 г. № 560-СФ.

${ }^{21}$ Об особо охраняемых зеленых территориях в городе Москве : постановление правительства Москвы от 22 августа 2012 г. № 423-ПП.

22 Об отнесении лесов, входивших до 1 июля 2012 г. в состав лесного фонда и включенных в границы города федерального значения Москвы, к зеленому фонду города Москвы и территорий, вошедших в зеленый фонд города Москвы, к особо охраняемой зеленой территории города Москвы : постановление правительства Москвы от 22 августа 2012 г. № 424-ПП.

${ }^{23} \mathrm{O}$ проектных предложениях по установлению границ природного комплекса с их описанием и закреплением актами красных линий : постановление правительства Москвы от 19 января 1999 г. № 38. 
комплекса (на всю территорию или на его часть), должен содержать требования и ограничения к осуществлению градостроительной деятельности.

Режимы регулирования градостроительной деятельности и содержание требований и ограничений в их границах устанавливались в постановлении правительства Москвы от 20 марта 2001 г. № 270-ПП «Об утверждении Положения о порядке установления линий градостроительного регулирования в городе Москве» (утратило силу в связи с принятием СПРИТ). В связи с тем что в настоящее время правовой акт, устанавливающий конкретные ограничения в границах режимов регулирования градостроительной деятельности, признан утратившим силу, понять содержание таких ограничений не представляется возможным.

Еще одним видом территорий, имеющим требования и ограничения по их использованию, являются территории внеуличных пешеходных переходов, также выделяемые линиями градостроительного регулирования в составе СПРИТ. Установить ограничения в границах данных территорий не представляется возможным. Конкретные ограничения в границах внеуличных пешеходных переходов в правовых актах г. Москвы не раскрываются.

Фактически указанная линия градостроительного регулирования образуется посредством установления в проектах планировки территории при планировании размещения внеуличного пешеходного перехода.

Границы внеуличных пешеходных переходов г. Москвы, выделяемые линиями градостроительного регулирования, могут порождать ограничения по использованию надземного или подземного пространства для осуществления градостроительной деятельности в границах их размещения в зависимости от вида внеуличного пешеходного перехода (надземный/подземный), но данное ограничение можно скорее назвать фрактическим, а не юридическим.

Другим видом территорий, имеющим требования и ограничения по их использованию, являются зоны транспортных коммуникаций, обозначающие границы территорий, предназначенных и используемых для размещения наземных транспортных коммуникаций (монорельсовый транспорт, подвесная канатная дорога транспортная, фруникулер транспортный, трамвай), согласно СПРИТ относятся также к иным территориям, на которых установлены ограничения использования земельных участков и объектов капитального строительства.

В правовых актах г. Москвы в отношении зон транспортных коммуникаций, так же как и в отношении внеуличных пешеходных переходов, не конкретизированы ограничения в границах указанных территорий, а их установление предусматривается проектами планировки территории.

Правовой статус и ограничения по осуществлению градостроительной деятельности в границах внеуличных пешеходных переходов и зон транспортных коммуникаций не установлены в правовых актах г. Москвы. Правовой статус территорий в границах данных линий градостроительного регулирования необходимо конкретизировать в целях исключения 


\section{Вестник ВГУ. Серия: Право}

неопределенности правового регулирования. Объем требований и ограничений, устанавливаемых в границах данных территорий непонятен.

Таким образом, установление в правовых актах г. Москвы требований и ограничений по осуществлению градостроительной деятельности, является примером особого порядка применения методов государственного управления, образующих совокупность способов (приемов) управляющего воздействия.

Учитывая особый статус г. Москвы как столицы Российской Федерации, установление в правовых актах г. Москвы требований и ограничений по осуществлению градостроительной деятельности позволяет органам исполнительной власти г. Москвы наилучшим образом реализовывать свои полномочия в области градостроительной деятельности и создает эффрективные способы (приемы) управляющего воздействия на объекты управления.

\section{Библиографический список}

Актуальные проблемы теории земельного права России / Е. Н. Абанина [и др.]. М. : Юстицинфором, 2020.

Алехин А. П., Карлолицкий А. А. Административное право России : учебник. М. : Зерцало-М, 2005.

Болтанова E. C. Ограничение прав в связи с установлением зоны с особыми условиями использования // Имущественные отношения в Российской Федерации. 2019. № 5.

Бутаева E. M. Юридическая сущность и значение государственного управления градостроительной деятельностью // Гражданин и право. 2011. № 10 .

Винниикий A. В., Харинов И. Н. Параметрирование строительства : модернизация регулирования и проблемы устранения избыточных ограничений // Рос. юрид. журнал. 2020. № 6.

Кудрякова О. В., Звягинцева Д. В. Проблемы соответствия административно-восстановительных мер Гражданскому кодексу Российской Федерации // Власть закона. 2018. № 1.

Маледов A. А. Административно-правовое регулирование контроля и надзора в государственном управлении // Административное право и процесс. 2018. № 1.

Салончик O. А. Правовое регулирование ограничений земельных прав сельскохозяйственных предприятий : дис. ... канд. юрид. наук. М., 1986.

Соколов А. Н. Муниципальное право и государственное управление в России / под ред. А. Г. Пархоменко. М. : ЮРКОМПАНИ, 2016.

Чередников A. B., Никишин В. В. Определение правового режима недвижимости в российском законодательстве // Рос. юрид. журнал. 2021. № 1.

Чиркин B. E. Государственное управление. Элементарный курс. М. : Юристъ, 2002.

Филаткина Ю. Е. Управление юридическими рисками, связанными с ограничением использования и хозяйственного оборота земельных участков // Имущественные отношения в Российской Федерации. 2019. № 3. 


\section{References}

Actual problems of the theory of land law in Russia / N. N. Abanina [et al.]. M. : Justicinform, 2020.

Alekhin A. P., Karmolitskiy A. A. Administrative law of Russia: textbook. M. : Zertsalo-M, 2005.

Boltanova E. S. Restriction of rights in connection with the establishment of a zone with special conditions of use // Property relations in the Russian Federation. 2019. № 5.

Butaeva E. M. Legal essence and significance of state management of urban planning activities // Citizen and Law. 2011. № 10.

Vinnitskiy A. $\quad$., Kharinov I. N. Parametrization of construction: modernization of regulation and problems of eliminating excessive restrictions // Russian legal journal. 2020. № 6 .

Kudryakova O. V., Zuyagintseva D. $\quad$. Problems of compliance of administrative and restorative measures with the Civil Code of the Russian Federation // Power of the Law. 2018. № 1.

Mamedov A. A. Administrative and legal regulation of control and supervision in public administration // Administrative law and process. 2018. № 1.

Samonchik O. A. Legal regulation of restrictions on land rights of agricultural enterprises : Dis. ... Cand. jurid. sciences. M., 1986.

Sokolov A. N. Municipal Law and Public Administration in Russia / edited by A. G. Parkhomenko. M. : YURKOMPANI, 2016.

Cherednikov A. V., Nikishin $V$. $V$. Determination of the legal regime of real estate in Russian legislation // Russian legal journal. 2021. № 1.

Chirkin V. E. Public administration. Elementary course. M. : Jurist, 2002. Filatkina $Y u$. E. Management of legal risks associated with limiting the use and economic turnover of land plots // Property relations in the Russian Federation. 2019. № 3.

\section{Для иитирования:}

Метальников В. Ю. Понятие и особенности использования градостроительных ограничений, устанавливаемых на территории города Москвы // Вестник Воронежского государственного университета. Серия: Право. 2021. № 3 (46). С. 209-221. DOI: https://doi.org/10.17308/vsu.proc.law.2021.3/3611

\section{Recommended citation:}

Metalnikov $V$. Yu. The concept and features of the use of urban planning restrictions established on the territory of the city of Moscow // Proceedings of Voronezh State University. Series: Law. 2021. № 3 (46). P. 209-221. DOI: https://doi.org/10.17308/vsu.proc. law. 2021. 3/3611

Национальный исследовательский университет "Высшая школа эконолики»

Метальников В. Ю., аспирант фбакультета права

E-mail:vmetalnikov@hse.ru
National Research University "Higher School of Economics"

Metalnikov V. Yu., Post-graduate Student of the Faculty of Law

E-mail:vmetalnikov@hse.ru 